\title{
(6) OPEN ACCESS \\ German translation and content validation of the OSTRC Questionnaire on overuse injuries and health problems
}

\author{
A Hirschmüller, ${ }^{1} \mathrm{~K}$ Steffen, ${ }^{2} \mathrm{~K}$ Fassbender, ${ }^{1}$ B Clarsen, ${ }^{2} \mathrm{R}$ Leonhard, ${ }^{3}$ \\ L Konstantinidis, ${ }^{1}$ N P Südkamp, ${ }^{1}$ E J Kubosch ${ }^{1}$
}

\begin{abstract}
- Additional material is published online only. To view please visit the journal online (http://dx.doi.org/10.1136/ bjsports-2016-096669).

1 Department of Orthopedics and Trauma Surgery, Center for Surgery, University of Freiburg - Medical Center, Freiburg, Germany

${ }^{2}$ Norwegian School of Sport Sciences, Oslo Sports Trauma Research Center, Oslo, Norway ${ }^{3}$ Department of Psychology, University of Freiburg, Freiburg, Germany
\end{abstract}

\section{Correspondence to} Dr A Hirschmüller, Department of Orthopedics and Trauma Surgery, Medical CenterUniversity of Freiburg, Center for Surgery, Hugstetter Str. 55 Freiburg im Breisgau D-79106, Germany;

anja.hirschmueller@uniklinikfreiburg.de

Accepted 30 September 2016 Published Online First 20 October 2016

CrossMark

To cite: Hirschmüller $A$, Steffen K, Fassbender K, et al. Br I Sports Med 2017:51:260-264.

\section{ABSTRACT}

Objective The aim of this study was to translate, culturally adapt and validate the Oslo Sports Trauma Research Centre (OSTRC) Questionnaire on Health Problems into the German context.

Methods A slightly modified back-translation method was used to translate the questionnaire. Validation was done in 24 high-level Paralympic athletes followed over 20 consecutive weeks.

Results The translated version of the questionnaire showed a very high internal consistency and good testretest reliability (Cronbach's $\alpha$ 0.92, intraclass correlation coefficient 0.91 ). Additionally, we observed high acceptance and compliance from our cohort of athletes, whose mean weekly response rate was $91.5 \%$. Overall, 114 training days were lost because of illness or injury within the 20 weeks and, on average, 5 athletes per week $(20.8 \%)$ reported health problems.

Conclusions This study demonstrates that the translated German version of the OSTRC Questionnaire is a reliable and valid tool with high internal consistency for the medical monitoring of German athletes. The OSTRC-G now offers the opportunity for a continued surveillance of high-level German athletes.

\section{INTRODUCTION}

The importance of a standardised injury and illness surveillance system in elite sports has recently often been highlighted. ${ }^{1}{ }^{2}$ Although surveillance systems have successfully been implemented in major international sporting events ${ }^{3-10}$ and a reduction in injury incidence following implementation of injury prevention strategies was demonstrated, ${ }^{11} 12$ continuous health monitoring of athletes in out-of-competition phases is rare. ${ }^{2}{ }^{13-15}$ Several studies have shown that much higher injury rates are reported when athletes are continuously monitored than when they are evaluated retrospectively. ${ }^{1} 1617$ Recent studies additionally showed that injury in the month before important championships is frequent and represents a risk factor for sustaining an injury during the championship. ${ }^{14} 1819$ In order to collect valid epidemiological data as well as to improve injury prevention programmes, continuous monitoring of injuries should therefore be aspired to. In 2013, Clarsen et $a l^{13}$ developed and validated the 'Oslo Sports Trauma Research Centre (OSTRC) Questionnaire on Health Problems' to capture all health problems of Norwegian high-level athletes. After having prospectively evaluated this questionnaire with their Norwegian Olympic and Paralympic athletes preparing for the London Games in 2012, the questionnaire has become part of the regular monitoring of their Olympic and Paralympic athletes. ${ }^{13}$

In contrast, until now there are no comparable monitoring tools available in German-speaking countries. Therefore, the aim of the present study was to translate and culturally adapt the OSTRC Questionnaire into the German context using an internationally recognised methodology followed by a validation of the translated questionnaire in a professional Paralympic athletes' cohort.

\section{MATERIALS AND METHODS \\ Methods}

The questionnaire

The OSTRC Questionnaire on Health Problems contains four key questions recording the level of participation and performance impairment and the degree of symptoms caused by injury or illness. A severity score is then calculated based on these four questions. ${ }^{13}$ Subsequent questions allow the athlete to report the anatomical location of injuries and list illness symptoms as well as to provide additional information about the problem such as the number of days of time loss, and whether they have received medical attention. The questionnaire was designed to be distributed weekly to all athletes being monitored, irrespective of their current health status, and was distributed electronically. The development of a smartphone app is actually in progress.

In our cohort, the questionnaire was set up on an internet open-source platform for scientific questionnaires (http://www.soscisurvey.de). The web link was distributed to the athletes via email. Approval to translate the questionnaire into German, validate and use it was obtained from the head of the research group in advance.

\section{Ethical approval}

The study was approved by the Ethics Committee of Albert-Ludwigs University Freiburg (approval 522/15) and complied with the Declaration of Helsinki.

\section{Translation and evaluation process}

The English version of the OSTRC Questionnaire on Health Problems was used for German translation. The translation of the questionnaire was conducted according to the guidelines published by Beaton $e t a l^{20}$ as well as a slightly modified backtranslation method described by Werner. ${ }^{21}$ 
The translation process included the following five steps: (1) forward translation by three independent English-German bilingual individuals; (2) primary evaluation of the comprehensibility of the translated questionnaire; (3) back translation into English by two English native speakers blinded to the original and the intended use of the questionnaire; (4) discussion in an expert committee and agreement on a final version; and (5) evaluation of the test-retest reliability and content validation in 24 highlevel Paralympic athletes.

1. Forward translation: three independent bilingual German residents (T1, T2 and T3), with German as their mother tongue, translated the entire English questionnaire into German. T1 and T2 were aware of the concepts being examined, whereas T3 was not. ${ }^{20}$ The project manager (AH) was one of the translators and participated in all steps in the adaptation process. ${ }^{22}$

2. Agreement: an initial consensus meeting was held with the three translators (T1, T2 and T3) to address discrepancies in the forward translations. A written report documented issues in relation to the translation process. ${ }^{20}$ Unresolved queries were cleared with the original developer. ${ }^{13}$

3. Evaluation of comprehensibility: twenty-four high-level German Paralympic athletes including three able-bodied tandem pilots were asked to complete the translated questionnaire and make suggestions for improving it.

4. The consensus questionnaire was then back translated by two German-speaking residents whose mother tongue is English (BT1 and BT2). BT1 and BT2 have no medical background but are postgraduate schoolteachers (mathematics, German and music) as well as professional medical English translators. BT1 and BT2 were both blinded to the purpose of the questionnaires and had no insight into the original English version. ${ }^{20}$

5. The German and English translated versions were then compared with the original versions to ensure conceptual equivalence; the remaining discrepancies and ambiguities were resolved in a consensus meeting among the project manager, the forward and backward translators. The original developer of the questionnaire was involved via email and telephone contact. $^{22}$

6. Validation: twenty-four Paralympic athletes completed the questionnaire during 20 consecutive weeks. In week 10, they were additionally asked how satisfied they were with the questionnaire and the project. At the end of the 20 weeks, a test-retest analysis was performed, the athletes being asked to complete the questionnaire twice within $48-72$ hours. They were also asked about the comprehensibility of each question and additional comments.

7. A final version of the questionnaire considering all the aforementioned aspects was generated, proofread and checked for errors of spelling and grammar; the layout was finalised by an expert committee consisting of the project manager, T2 and T3, as well as an independent research sports scientist. $^{20}$

\section{Athletes and recruitment}

The initial cohort was defined as all members of the national paracycling team Germany (26 high-level athletes including 3 able-bodied tandem pilots). Twenty-four athletes agreed to participate and signed written informed consent forms.

The participants' demographics are summarised in table 1 . After signing the consent form, athletes were contacted each week via email and reminded 2 days later if the questionnaire had not been turned in.
Table 1 Participants' characteristics

\begin{tabular}{ll}
\hline Participants & 24 \\
Sex & 17 male, 7 female \\
Age & $37.8 \pm 10.4$ years $(25-55$ years) \\
Sport & $\begin{array}{l}21 \text { paracyclists }(9 \times \text { handbike, } 8 \times \text { bicycle, } 2 \times \text { tricycle, } \\
2 \times \text { tandem); }\end{array}$ \\
& 3 able-bodied tandem pilots \\
Weekly training volume & $14.4 \pm 1.4$ hours \\
Athlete days & $20 \times 7 \times 24=3360$ \\
Lost training days & $114(3.4 \%$ of athlete days) \\
\multicolumn{1}{c}{ Because of illness } & 90 (mean $3 \pm 3.9$ per illness) \\
Because of injury & 24 (mean $1 \pm 1.4$ per injury) \\
Time to complete & $90.5 \pm 20.7 \mathrm{~s}$ \\
OSTRC-G & $91.5 \pm 5.4 \%$ \\
Response rate & paraplegia/tetraplegia $\mathrm{n}=10$, limb pathologies $\mathrm{n}=7$, \\
Handicap & cerebral impairments $\mathrm{n}=2$, visual impairments $\mathrm{n}=2$ \\
\hline
\end{tabular}

\section{Statistics}

Instruments used for individual assessment in clinical practice should reveal high test-retest reliability, that is, an intraclass correlation coefficient (ICC) of at least $0.90 .^{23} 24$

We included 24 participants in the monitoring study and 19 participants in the test-retest analysis. Internal consistency was determined by calculating Cronbach's $\alpha$ with 0 indicating no internal consistency and 1 corresponding to perfect internal consistency. ICC was calculated from the test-retest measurement to analyse reliability. Statistical analysis was processed using SPSS V.23.0.

\section{RESULTS \\ Translation and adaptation}

There were no major problems with the questionnaire's forward translation process. Minor discrepancies included the synonymic use of nouns explaining symptoms or localisation of injury, the use of singular versus plural, use of past tense or perfect, sentence structure and the use of prepositions. Typical examples are 'vergangene Woche=past week' instead of 'letzte Woche=last week', 'gesundheitliche Probleme=health problems' instead of 'gesundheitliche Beschwerden=health complaints', 'In großem Umfang=to a major extent' instead of 'in beträchtlichem Umfang $=$ to a considerable extent'.

A few times, intentional changes to the literal interpretation and syntax of the original questionnaire were made. In the original questionnaire, the authors used headings in some of the answers to questions 1-3 (no reduction, to a minor extent, to a moderate extent), whereas the last answer always included a verb (cannot participate at all). We discussed keeping this structure instead of changing it to consistently use headings only ('no participation' instead of 'cannot participate at all'). We decided for a compromise 'no participation possible'. Additionally, a question about training volume was added to the questionnaire following the suggestion by several athletes.

Two unresolvable problems were identified and clarified by contacting the original researcher. First, the meaning of 'fainting' was cleared to mean a genuine syncope involving a loss of consciousness rather than 'dizziness/feeling faint/presyncope'. Second, 'to a major extent' is considered equivalent to 'to a severe extent' and can thus be used synonymously. 


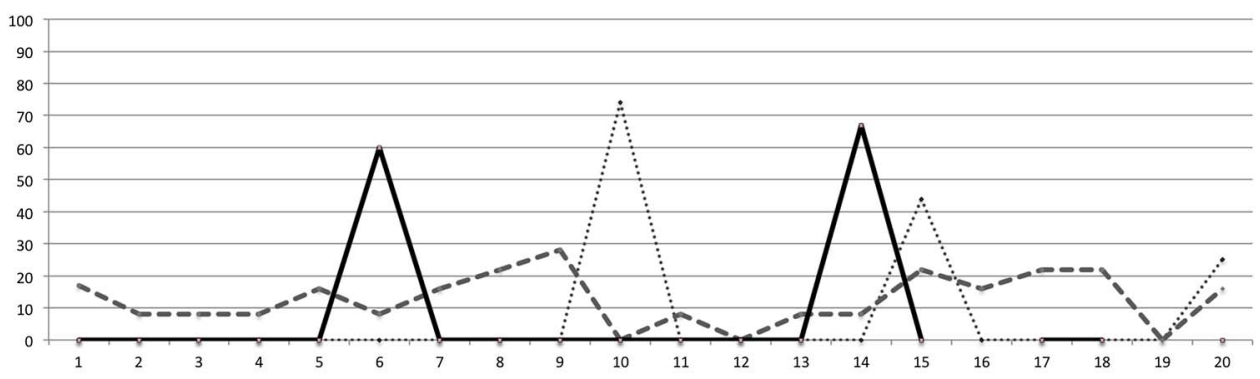

Figure 1 Three typical courses of the injury and illness severity score over the 20 consecutive weeks fluctuations

\section{Validation/follow-up}

All 24 athletes were followed over 20 consecutive weeks. There were 17 male and 7 female athletes. Three athletes were ablebodied tandem pilots. The athletes' characteristics are presented in table 1 .

Out of the 24 athletes, 17 showed a very high compliance with a maximum of one missing questionnaire within the 20 weeks. In total, 439/480 questionnaires were returned, corresponding to a response rate of $91.5 \%$. In 100 of the questionnaires, illnesses or injuries were documented, corresponding to five athletes per week (20.8\%) reporting health problems. While 10 athletes weekly returned all 20 questionnaires, most of this cohort had a varying response rate, ranging from 5\% to 35\% missing surveys. A blind athlete, who needed help to complete the survey, had the highest missing rate (70\%).

Overall, 114 lost training days because of illness or injury were reported, split into 90 days attributed to illnesses and 24 to injuries. On average, 3.0 03.9 training days were lost per illness, while a mean of $1.0 \pm 1.4$ training days were lost per injury. In our cohort of 24 athletes, there were a total of 5.0 \pm 5.2 lost training days per week because of illness, and 1.2 \pm 1.3 days per week because of injuries.

\section{Test-retest}

A test-retest analysis was possible in 19 participants. No major intraindividual disagreements were observed in the test-retest answers on the first and the second return. The questionnaire demonstrated very good reliability with an ICC of 0.91 for the injury severity index.

Mean values for Cronbach's $\alpha$ within the 20 weeks ranged from 0.67 to 0.98 with a mean value of 0.92 , showing high internal consistency. Lower Cronbach's $\alpha$ was associated with low variance at this measurement point (the range restriction in the items being the primary reason for the low $\alpha$ value). All the participating athletes rated the questionnaire and all items on it as being 'understandable'. Suggestions for linguistic improvement were minor. Several athletes suggested independently that a question be added about the weekly training volume. Acceptance of the injury and illness surveillance project was also queried, and was rated very high.

Injury severity scores (ISS) ranged from 0 to 100 , with the mean scores ranging from 1.7 to 21.1 , respectively. These scores revealed considerable floor effects, as most of the participants marked very low values primarily. We identified two main patterns after having analysed individual ISS over the 20-week observation period (figure 1). Several athletes had one or two peaks, with almost all their other values (including those in the week before and after the peaks) being zero (figure 1 continuous and dotted line). This would be typical of a respiratory tract infection. In contrast, other athletes had a persistent, slightly elevated score fluctuating over a longer time span, which would be typical of a low-grade overuse injury or a chronic illness (figure 1 broken line).

\section{DISCUSSION}

The importance of a valid monitoring tool for injury and illness surveillance in high-level athletes has been emphasised numerous times in recent years. The OSTRC Questionnaire on Health Problems was developed and validated at the OSTRC in Norway. The questionnaire is of very good test quality and enjoys a high level of acceptance by athletes. ${ }^{13}$

\section{Translation and adaption}

Until now, there had been no comparable questionnaire available in the German language. Therefore, an internationally recognised methodology was applied to translate the OSTRC Questionnaire into German and adapt it to the German context. $^{202425}$ After independent forward and backward translations, a consensus meeting with all translators and a neutral, uninvolved sports scientist was held for harmonisation. The translated questionnaire was also context-validated by a cohort of 24 high-level Paralympic athletes including 3 able-bodied tandem pilots over 20 consecutive weeks, and subjected to testretest evaluation.

Our results clearly show that the German version of the OSTRC Questionnaire is valid, reliable and acceptable for use in a German elite athlete population. No major disagreements were observed between the OSTRC and the back-translated version of the OSTRC Questionnaire in a German context. This observation is in line with two published translations of the OSTRC Questionnaire into Swedish ${ }^{25}$ and Danish. ${ }^{24}$ However, two main conflicts were raised and discussed by the harmonisation committee. Both conflicts were clarified with the research team of the original questionnaire ${ }^{13}$ and matched accordingly. According to the repeated suggestion made by different athletes of having recorded the training volume, we added a question about weekly training volume to the questionnaire. Such an addition was also reported during the adaptation process of the Swedish translation published by Ekman et al. ${ }^{25}$ The Swedish group finally used two open background questions on the time of exposure during training as well as on exposure during competition. In the German version, we only added one question about the sum training volume per week (hours/miles per week). The original questionnaire was designed to be flexible, allowing project-specific and context-specific questions such as sporting exposure to be added at the end.

\section{Response rate}

Overall, we observed very high acceptance and compliance from our cohort of athletes, whose response rate was $>90 \%$. More than $70 \%$ of the athletes $(17 / 24)$ had not more than a 
maximum of one missing questionnaire over the 20-week period. Only two athletes missed more than $20 \%$ of the questionnaires, one of whom was a blind athlete who needed personal assistance to complete the questionnaire. These findings on high response rates confirm the results published by the Norwegian, Swedish and Danish groups. 2425

\section{Test-retest}

We conducted a test-retest analysis also, distributing the questionnaire twice within 48-72 hours. Nineteen participants successfully returned both questionnaires. No major intraindividual disagreements were observed in the test-retest answers; the ISS' ICC amounted to 0.91. This reinforces the results of Jorgensen et $a l,{ }^{24}$ who reported considerably lower ICC values after a test-retest period lasting 2 weeks $(\mathrm{ICC}=0.62)$ than that lasting 1 week $(\mathrm{ICC}=0.72)$. A longer period of time may allow too much time for natural changes in the severity of injuries and illnesses to occur, which may make the questionnaire seem less reliable than it actually is. Of course, memory effects or a recall bias must be assumed when using a brief period of 2-3 days for retest. ${ }^{26}$ However, the very high variability of the attributes and the sum score must be considered in this context. Considerable change is possible even during a single training session. The questionnaire is distributed regularly on a weekly basis in order to capture even minor problems in athletes' training habits, performance and well-being as early as possible. We thus did not think a longer time frame would have facilitated the assessment of test-retest reliability as the findings of Jorgensen et $a l^{24}$ could show. This preliminary assumption was supported by our analysis of the individual ISS over the 20 weeks. We noted strong fluctuations in intraindividual ISS/values from 1 week to the next. In our opinion, the ICC would, therefore, lose validity in conjunction with a longer test-retest interval.

The mean Cronbach's $\alpha$ value over the 20 weeks was 0.92 , showing high internal consistency. This concurs with the results of Clarsen et $a l^{27}$ reporting Cronbach's $\alpha$ of 0.91 as well as Jorgensen et al. ${ }^{24}$

\section{Injury severity score}

Weekly absolute ISS ranged from 0 to 100 , while mean ISS ranged from 1.7 to 21.1 , respectively. The considerable fluctuations from 1 week to the next can be interpreted as success for this monitoring tool, assuming that a prompt reaction by the medical team has a high impact on the history of the injury/ illness resulting in rapid recovery. On average, over a fifth of the athletes on average reported health problems per week, leading up to a total of 114 lost training days. These results highlight the need for and importance of an injury and illness surveillance system, not just during major sport events, but also in periods between events, to identify any early health-related risks of injury and other physical symptoms. One could also argue that athletes are more susceptible to symptoms even when they are perceived as quite minor and that they tend to rate their consequences rather high. Some athletes revealed a slightly elevated score fluctuating persistently over a rather long time span. This finding can either be interpreted as reflecting a tendency to report symptoms, or as an athlete suffering from a subacute illness/disease that they tolerate, although it seems to impair their training or performance. In the authors' opinion often working with disabled athletes it is more likely to be the latter; tolerating chronic problems, rather than presenting with symptoms. However, there is still high individual variability. With an increasing sample size in the future, cluster analysis will enable us to match types.

\section{Perspectives}

This study demonstrates that the translated German version of the OSTRC Questionnaire is a reliable and valid tool with high internal consistency for the medical monitoring of German athletes. The German Questionnaire thereby confirmed the results of the Swedish ${ }^{25}$ and the Danish translations. ${ }^{24}$

The translated OSTRC Questionnaire therefore offers the opportunity for a continued surveillance of high-level German athletes in order to monitor and promptly treat medical conditions. Our experience in conducting this study supports that of Clarsen $e t a l^{2}$ who contended that a fast reaction to potential medical problems can considerably expedite rapid recovery. Long-term observations of a larger cohort of Olympic and Paralympic athletes from different disciplines and with different handicaps should be conducted to deepen our knowledge of injury and illness prevalence in various sports, different athletic groups and in different levels of athletic intensity.

\section{What are the findings?}

- A German version (Oslo Sports Trauma Research Centre (OSTRC)-G) of the well-established OSTRC Questionnaire on health problems has successfully been implemented.

- The OSTRC-G questionnaire showed a very high internal consistency and good test-retest reliability.

- The acceptance of the OSTRC-G questionnaire in German top-level athletes was high.

- The mean weekly rate of health problems in German Paralympic athletes was $21 \%$.

\section{How might it impact on clinical practice in the future?}

- Continuous medical monitoring of German-speaking athletes can now be implemented in a different population.

- By weekly administration of the OSTRC-G questionnaire, medical problems can be depicted and treated very early.

- Surveillance of top-level athletes with the OSTRC-G questionnaire should be aspired in preparation and competition phases.

Acknowledgements The authors are grateful to the two professional translators Carole Cürten and Duncan Cummins as well as to the sports scientist Anja Wehrle for their important contribution to the translation procedure, as well as to all the athletes who so meticulously completed the questionnaires. The authors' acknowledgement is also extended to Romana Brunner for collegial discussions and cession of their survey for comparisons.

Contributors $\mathrm{AH}$ conceived and designed the study with the help of EJK, KS and LK. KF, EJK and AH carried out the data acquisition. KS and BC helped in data processing and in the optimisation of the German version of the questionnaire. $\mathrm{AH}$, RL, EJK and KF undertook the data analyses. All authors contributed to the data interpretation. AH drafted the manuscript with input from all the authors. All authors approved the final manuscript.

Competing interests None declared.

Patient consent Obtained.

Ethics approval University of Freiburg Ethical Committee (approval 522/15).

Provenance and peer review Not commissioned; externally peer reviewed.

Open Access This is an Open Access article distributed in accordance with the Creative Commons Attribution Non Commercial (CC BY-NC 4.0) license, which 
permits others to distribute, remix, adapt, build upon this work non-commercially, and license their derivative works on different terms, provided the original work is properly cited and the use is non-commercial. See: http://creativecommons.org/ licenses/by-nc/4.0/

\section{REFERENCES}

1 Ekegren CL, Gabbe BJ, Finch CF. Sports injury surveillance systems: a review of methods and data quality. Sports Med 2016;46:49-65.

2 Clarsen B, Rønsen 0, Myklebust G, et al. The Oslo Sports Trauma Research Center questionnaire on health problems: a new approach to prospective monitoring of illness and injury in elite athletes. Br J Sports Med 2014;48:754-60.

3 Alonso JM, Edouard $\mathrm{P}$, Fischetto $\mathrm{G}$, et al. Determination of future prevention strategies in elite track and field: analysis of Daegu 2011 IAAF Championships injuries and illnesses surveillance. Br J Sports Med 2012;46:505-14.

4 Alonso JM, Junge A, Renström P, et al. Sports injuries surveillance during the 2007 IAAF World Athletics Championships. Clin J Sport Med 2009;19:26-32.

5 Alonso JM, Tscholl PM, Engebretsen L, et al. Occurrence of injuries and illnesses during the 2009 IAAF World Athletics Championships. Br J Sports Med 2010;44:1100-5

6 Edouard P, Depiesse F, Hertert P, et al. Injuries and illnesses during the 2011 Paris European Athletics Indoor Championships. Scand J Med Sci Sports 2013;23: e213-18.

7 Engebretsen L, Steffen K, Alonso JM, et al. Sports injuries and illnesses during the Winter Olympic Games 2010. Br J Sports Med 2010;44:772-80.

8 Junge $A$, Engebretsen L, Mountjoy ML, et al. Sports injuries during the Summer Olympic Games 2008. Am J Sports Med 2009;37:2165-72.

9 Mountjoy $M$, Junge $A$, Alonso JM, et al. Sports injuries and illnesses in the 2009 FINA World Championships (Aquatics). Br J Sports Med 2010;44:522-7.

10 Ruedl G, Schobersberger W, Pocecco E, et al. Sport injuries and illnesses during the first Winter Youth Olympic Games 2012 in Innsbruck, Austria. Br J Sports Med 2012;46:1030-7.

11 Webborn N. London 2012 Paralympic Games: bringing sight to the blind? Br J Sports Med 2013;47:402-3.

12 Willick SE, Webborn N, Emery C, et al. The epidemiology of injuries at the London 2012 Paralympic Games. Br J Sports Med 2013;47:426-32.

13 Clarsen B, Myklebust G, Bahr R. Development and validation of a new method for the registration of overuse injuries in sports injury epidemiology: the Oslo Sports Trauma Research Centre (OSTRC) overuse injury questionnaire. Br J Sports Med 2013;47:495-502.
14 Mountjoy M, Junge A, Alonso JM, et al. Consensus statement on the methodology of injury and illness surveillance in FINA (aquatic sports). Br J Sports Med 2016;50:590-6.

15 Timpka T, Alonso JM, Jacobsson J, et al. Injury and illness definitions and data collection procedures for use in epidemiological studies in Athletics (track and field): consensus statement. Br J Sports Med 2014;48:483-90.

16 Junge A, Dvorak J. Influence of definition and data collection on the incidence of injuries in football. Am J Sports Med 2000;28:S40-6.

17 Bjørneboe J, Flørenes TW, Bahr R, et al. Injury surveillance in Male professional football; is medical staff reporting complete and accurate? Scand J Med Sci Sports 2011;21:713-20

18 Alonso JM, Jacobsson J, Timpka T, et al. Preparticipation injury complaint is a risk factor for injury: a prospective study of the Moscow 2013 IAAF Championships. $\mathrm{Br}$ J Sports Med 2015;49:1118-24.

19 Edouard P, Depiesse F, Branco P, et al. Analyses of Helsinki 2012 European Athletics Championships injury and illness surveillance to discuss elite athletes risk factors. Clin J Sport Med 2014;24:409-15.

20 Beaton DE, Bombardier C, Guillemin F, et al. Guidelines for the process of cross-cultural adaptation of self-report measures. Spine 2000;25:3186-91.

21 Werner C. Translating, wording through interpreters, and the problem of decentering. In: Naroll R CR, ed. A handbook of method in cultural anthropology. New York: American Museum of Natural History, National History Press, 1970:974-89.

22 Wild D, Grove A, Martin M, et al. Principles of good practice for the translation and cultural adaptation process for patient-reported outcomes (PRO) measures: report of the ISPOR Task Force for Translation and Cultural Adaptation. Value Health 2005;8:94-104

23 de Vet HCW, Terwee CB, Mokkink LB, et al. Measurement in medicine: a practical guide. Cambridge: Cambridge University Press, 2011. http://ebooks.cambridge.org/ ebook.jsf ?bid=CB09780511996214

24 Jorgensen JE, Rathleff CR, Rathleff MS, et al. Danish translation and validation of the Oslo Sports Trauma Research Centre questionnaires on overuse injuries and health problems. Scand J Med Sci Sports 2015.

25 Ekman E, Frohm A, Ek P, et al. Swedish translation and validation of a web-based questionnaire for registration of overuse problems. Scand I Med Sci Sports 2015;25:104-9.

26 Streiner DL, Norman GR, Cairney J. Health measurement scales: a practical guide to their development and use. Oxford: Oxford Medical Publications, 2014.

27 Clarsen B, Bahr R, Heymans MW, et al. The prevalence and impact of overuse injuries in five Norwegian sports: application of a new surveillance method. Scand J Med Sci Sports 2015;25:323-30. 